\title{
O PAPEL DAS PISTAS DO CONTEXTO VERBAL NO RECONHECIMENTO DE PALAVRAS
}

\author{
Sandra Regina Kirchner Guimarães
}

\begin{abstract}
RESUMO. O processo de leitura é estudado principalmente com base em dois modelos teóricos: o ascendente (bottom-up), baseado na concepção que considera o desempenho em leitura dependente do processo de decodificação, e o descendente (top-down), fundamentado na concepção que defende que a leitura se apóia especialmente na utilização de informações sintático-semânticas do texto. O presente estudo teve por objetivo investigar a contribuição do uso de informações do contexto verbal no reconhecimento de palavras. De acordo com os resultados obtidos, os sujeitos com dificuldades na leitura apoiaram-se no contexto verbal para compensar suas dificuldades, lendo corretamente $75,24 \%$ das palavras apresentadas.
\end{abstract}

Palabras clave: leitores principiantes, reconhecimento de palavras, contexto verbal.

\section{THE ROLE OF VERBAL-CONTEXT CLUES IN THE WORD-RECOGNITION PROCESS}

\begin{abstract}
The reading process is studied mainly with basis on two theoretical models: the bottom-up model - based on the conception that considers the reading performance as being dependent on a decoding process, and the top-down model based on the conception that the reading ability relies mainly on the use of syntactic-semantic information present in the text. This study was targeted at determining the importance of using information provided by the verbal context in recognizing words. Pursuant to the results attained, the subjects with reading problems found support in verbal context to compensate their difficulties, being able to read correctly about $75.24 \%$ of the words presented.
\end{abstract}

Key words: beginning readers, word recognition, verbal context.

A partir do final da década de1970 e início da de 1980, as pesquisas nas áreas da psicologia cognitiva, do desenvolvimento e da neuropsicologia cognitiva lograram enormes progressos, renovando as concepções teóricas acerca dos mecanismos de aquisição e desenvolvimento da leitura.

$\mathrm{O}$ que se verifica atualmente é que diferentes enfoques sobre a linguagem escrita têm gerado modelos teóricos antagônicos, que são irreconciliáveis, pois se originam de pressupostos epistemológicos opostos. De acordo com Cunningham e Fitzgerald (1996), as principais divergências relacionam-se à concepção sobre a origem e localização do significado na linguagem escrita, à importância relativa dos dados sensoriais e da informação mental para produzir ou recuperar o significado e, finalmente, ao desacordo a respeito de ser o significado descoberto ou criado.
Em um extremo, tem-se a concepção que considera a escrita apenas como um código para transcrever o discurso. O significado é uma propriedade do discurso, e não do texto escrito. De acordo com esta concepção, texto e sujeito são completamente separados, sendo o primeiro utilizado para transmitir mensagens entre emissor e receptor, de forma que o papel do sujeito é apenas reconhecer os sinais gráficos e transformá-los em discurso. Logo, pode-se dizer que o significado já vem dado no texto e deve ser descoberto. Baseados nessa concepção, têmse os modelos de leitura de orientação ascendente (bottom-up), os quais caracterizam a leitura como um processo de decodificação. Esses modelos sugerem que a compreensão de um texto como um todo se torna mais eficiente apenas quando as palavras são lidas corretamente e com certa rapidez. Em outras palavras, frente ao material escrito, o leitor deve primeiramente discriminar visualmente as letras, sílabas e palavras para depois relacioná-las aos seus

* Doutora em Psicologia, Professora Adjunto II do Departamento de Teoria e Fundamentos da Educação, Universidade Federal do Paraná. 
sons (decodificação); o leitor só poderá relacionar as palavras decodificadas aos significados após esse processo. Assim, modelos de leitura baseados nessa concepção destacam a consciência fonológica ${ }^{1}$ como um fator cognitivo decisivo no desenvolvimento da leitura e apontam como explicação para as dificuldades de aprendizagem dessa atividade os problemas apresentados pelos sujeitos em relação à análise fonológica.

O papel central da consciência fonológica sobre a aprendizagem da leitura e da escrita é atestado pelos resultados de numerosos trabalhos de pesquisa que submeteram indivíduos - de diversas idades cronológicas e diferentes níveis léxicos - a várias provas de análise fonológica. Esses estudos têm demonstrado que o desempenho das crianças préescolares, em determinadas tarefas de consciência fonológica, relaciona-se com o sucesso na aquisição da leitura e da escrita (Stanovich, Cunningham \& Cramer, 1984; Yopp, 1988). Há também evidência de que o treinamento da consciência fonológica pode exercer influência benéfica na aprendizagem dessas atividades (Byrne \& Fielding-Barnsley, 1993; Williams, 1980), sobretudo quando associado ao treinamento do reconhecimento das correspondências entre as letras e os sons (Byrne, 1996)

Em outro extremo, situa-se a concepção que considera o texto e o leitor como partes de um sistema social no qual o significado é produzido. A (re)construção do significado do texto é essencialmente um processo mental; portanto, o leitor é percebido não como um simples decodificador, mas como aquele que assume um papel atuante, que busca significações. Com essa concepção identificam-se autores como Goodman (1987) e Smith (1984, 1997/1999), que apóiam os modelos de leitura de orientação descendente (top-down). Segundo esses autores, o "bom" leitor é aquele que não depende exclusivamente do processo de decodificação, mas que é capaz de identificar as palavras dedutivamente, a partir da utilização de pistas sintático-semânticas ${ }^{2}$. Portanto, os modelos de orientação descendente

1 Neste artigo, seguindo a tendência de outros autores (Byrne, 1996; Rego, 1995), será utilizado o termo consciência fonológica para designar a consciência dos segmentos que compõem a fala (rimas, aliterações, sílabas e fonemas) e o termo consciência sintática será utilizado para indicar a capacidade de refletir e manipular mentalmente a estrutura gramatical das sentenças.

2 Pistas sintáticas são as informações relativas as palavras considerando a sua classificação enquanto categoria gramatical e a sua posição na frase. Já as pistas semânticas informam sobre o sentido das palavras e das frases do texto. destacam o papel da consciência sintática e semântica na aquisição e desenvolvimento da leitura, considerando secundário o papel de processos cognitivos subjacentes como, por exemplo, processamento fonológico. Para esses modelos, as dificuldades de leitura estão primeiramente relacionadas com a pouca capacidade de usar o contexto verbal (sentido do texto) produtivamente.

Assim, se por um lado existem numerosas evidências apontando a decodificação e as habilidades metalingüísticas diretamente a ela relacionadas como determinantes no desenvolvimento da leitura, por outro lado existem vários estudos que destacam a importância da utilização das informações sintáticas e semânticas para a aquisição e aperfeiçoamento da leitura.

Um dos primeiros estudos que forneceram sustentação a essa idéia foi o de Guthrie (1973). Ele comparou um grupo de crianças de 10 anos que apresentavam dificuldades de leitura com um grupo de crianças de sete anos; ambos os grupos apresentavam nível de leitura equivalente a sete anos de idade. $\mathrm{O}$ pesquisador constatou que as crianças mais novas com nível de leitura adequado para a sua idade tiveram um desempenho significativamente melhor que as crianças mais velhas em uma tarefa de leitura na qual as crianças eram solicitadas a escolher, a cada cinco palavras (aproximadamente), qual dentre três alternativas seria a palavra correta a inserir naquele ponto no texto. Os dados obtidos nesse estudo levaram Guthrie (1973) a concluir que as crianças com dificuldades de leitura têm menor habilidade que as outras para utilizar pistas gramaticais na leitura.

Em estudo posterior, Perfetti, Goldman e Hogaboam (1979) verificaram que "bons" leitores não dependiam das pistas do contexto para reconhecer palavras na leitura, embora exibissem uma aptidão superior à dos "maus" leitores para fazer uso de pistas contextuais em tarefas destinadas a medir essa habilidade.

Nessa perspectiva, Stanovich (1980) propõe a teoria interativo-compensatória, segundo a qual tanto o "mau" leitor quanto o leitor principiante, para compensar suas habilidades pouco proficientes no processo de decodificação (no nível de correspondência grafema-fonema), recorrem a pistas sintáticas e semânticas do contexto verbal para reconhecer as palavras no texto. Já o leitor fluente, pela sua habilidade de reconhecer palavras, independentemente do contexto, não teria necessidade dessa compensação.

Tunmer (1990) e Tunmer e Hoover (1992) levantam possíveis razões pelas quais a habilidade de 
previsão na leitura é associada com uma maior proficiência na mesma, apontando uma relação entre consciência sintática e aprendizagem da leitura. Afirmam os autores que há, no mínimo, duas maneiras pelas quais a consciência sintática pode influenciar o desenvolvimento da leitura: ela possibilita a monitoração eficiente do processo de compreensão; ela auxilia na aquisição da habilidade de decodificação fonológica.

Em relação à influência da consciência sintática na habilidade de decodificação fonológica, os referidos autores explicam que, no caso das palavrasregra, os leitores podem fazer uso do contexto para solucionar seus problemas pendentes de decodificação. Por exemplo, um sujeito que não conhece a regra ortográfica segundo a qual a letra $s$ entre duas vogais tem som de /z/ poderia ler sem dificuldade a palavra coisa quando ela aparecesse no contexto de uma sentença, embora não pudesse ler corretamente (empregando a mesma regra ortográfica) a palavra inventada foisa. Assim, com a utilização constante do contexto para solucionar as suas dificuldades de decodificação, a criança termina abstraindo a regra ortográfica e automatizando a ortografia.

Já no caso das palavras irregulares, aquelas cuja grafia não pode ser prevista por regras, vários pesquisadores têm argumentado que a habilidade para usar o contexto pode ajudar leitores iniciantes a reconhecê-las. Considera-se que nenhuma palavra tem ortografia totalmente arbitrária: mesmo as que representam exceções fornecem pistas fonológicas precisas para a sua identificação (Cough \& Hillinger, citados por Tunmer \& Hoover, 1992; Van Orden, 1987). Portanto, os leitores iniciantes, ao empregar as regras de correspondência grafema-fonema, produzirão um resultado suficientemente semelhante à forma fonológica das palavras que constituem exceção, de forma que as pistas do contexto da sentença podem ser utilizadas para alcançar seu reconhecimento exato.

Não obstante, Tunmer, Nesdale e Wright (1987), ao considerarem a diversidade de resultados dos estudos que relacionam as habilidades metalinguiísticas (consciência fonológica e consciência sintática) ao desenvolvimento da leitura, formularam a hipótese de que a aprendizagem inicial da leitura era influenciada tanto pela consciência fonológica quanto pela consciência sintática. A primeira influenciaria diretamente a aquisição das correspondências fonema-grafema ligada ao processo de decodificação; enquanto a segunda possibilitaria o uso do contexto para identificar as palavras não-familiares. Isso aumentaria o conhecimento das correspondências grafema-fonema, facilitando, conseqüentemente, o processo de decodificação pela criança.
Para testar essa hipótese, Tunmer, Herriman e Nesdale (1988) conduziram um estudo com 100 crianças australianas, nas quais foram administradas uma tarefa de consciência sintática (corrigir sentenças incorretas) e uma tarefa de consciência fonológica (contar os fonemas de palavras sem sentido). Os pesquisadores constataram uma relação preditiva entre esses dois aspectos da consciência metalingüística e o desenvolvimento da capacidade da criança na decodificação e compreensão da leitura. Os dados desse estudo revelam que muitas crianças com bom desempenho em tarefas de consciência sintática apresentaram dificuldades na decodificação de palavras inventadas, e que nenhuma criança com fraco desempenho nesse tipo de tarefa decodificou bem palavras inventadas. Assim, os autores sugerem que a consciência sintática pode ser essencial na aquisição do conhecimento das correspondências grafemafonema. No entanto, essa sugestão está baseada em resultados puramente correlacionais, necessitando de investigação mais aprofundada.

Mais recentemente, Gottardo, Stanovich e Siegel (1996) realizaram um estudo que investigou a relação entre sensibilidade fonológica, processamento sintático ${ }^{3}$ e memória verbal de curto prazo com o desempenho em leitura de crianças da $3^{a}$ série (falantes do inglês). De acordo com os pesquisadores, os dados levantados indicam que a sensibilidade fonológica, isoladamente, é um forte preditor do desempenho em leitura, enquanto a habilidade de processamento sintático não é preditiva da capacidade de reconhecimento de palavras, leitura de palavras inventadas ou compreensão da leitura. Para os autores, esses resultados sustentam a hipótese da limitação do processamento fonológico de Shankweiler, Crain, Brady e Macaruso (1992), segundo a qual os problemas no processamento fonológico tornam-se um "gargalo" que impede a operação de outros processos cognitivos de nível mais elevado. Desse modo, as correlações entre as dificuldades na leitura e a consciência sintática deficiente surgem como um epifenômeno das deficiências no processamento fonológico.

Com relação aos estudos em português, verifica-se que o número de pesquisas relacionando consciência sintática e aprendizagem da leitura e da escrita é bastante reduzido, e que, ao contrário de trabalhos cujo enfoque é

\footnotetext{
Gottardo, Stanovich e Siegel (1996, p. 565) defendem que o termo "consciência fonológica" seja substituído por "sensibilidade fonológica" para designar os diferentes níveis de habilidade fonológica, os quais podem envolver unidades silábicas, subsilábicas ou fonêmicas. Além disso, é importante destacar que os autores utilizam o termo "habilidade de processamento sintático" para se referir à "consciência sintática".
} 
sintática e aprendizagem da leitura e da escrita é bastante reduzido, e que, ao contrário de trabalhos cujo enfoque é a consciência fonológica, não existe concordância entre os resultados obtidos. Por exemplo, um primeiro estudo realizado por Rego (1993), envolvendo 32 crianças brasileiras que freqüentavam uma escola de orientação construtivista, mostrou que a consciência sintática constitui-se um bom preditor do progresso das crianças tanto na decodificação quanto na compreensão da leitura. Entretanto, um outro estudo de Rego (1995), envolvendo 50 crianças brasileiras alfabetizadas por meio de um método tradicional - com ênfase exclusiva no ensino de padrões silábicos - apresentou resultados diferentes: não foi encontrada uma conexão entre consciência sintática e progresso inicial em decodificação.

Barrera (2000), que efetuou um estudo com 65 crianças da $1^{\mathrm{a}}$ série falantes do português, testou a hipótese de que habilidades metalingüísticas como consciência fonológica, lexical e sintática desempenham um papel facilitador na aquisição da linguagem escrita e que a utilização de variedades lingüísticas não-padrão dificulta essa aquisição. Os resultados dessa investigação mostraram correlações positivas entre os níveis de consciência fonológica e sintática no início do ano letivo e o desempenho em leitura e escrita no final do ano. Entretanto, a consciência lexical apresentou uma correlação significativa apenas com o nível de leitura verificado no final do ano. Por outro lado, os níveis de variação lingüística, embora tenham mostrado uma tendência em se relacionar negativamente com os desempenhos em leitura e escrita, apresentaram uma correlação significativa apenas com o resultado final em leitura. A pesquisadora concluiu que, de fato, os alunos que iniciaram o processo de alfabetização com níveis mais avançados de habilidades metalingüísticas e níveis mais baixos de variação lingüística apresentaram melhor desempenho em leitura e escrita no final do ano letivo.

De qualquer maneira, embora os resultados de Barrera (2000) corroborem os encontrados em um dos estudos de Rego (1993), o fato de haver resultados contraditórios entre as pesquisas aponta para a necessidade de investigações novas e mais profundas com sujeitos falantes do português.

Em suma, o contexto no qual o presente estudo se insere apresenta consenso a respeito da importância da consciência fonológica para o desenvolvimento da leitura, mas é reduzido o número de estudos analisando a influência da consciência sintática sobre esse desenvolvimento. Do mesmo modo, são poucos os estudos que analisam o benefício da utilização do contexto verbal sobre o desempenho em leitura. Por isso, a condução desta pesquisa teve como objetivo central avaliar a contribuição do uso de pistas contextuais no reconhecimento de palavras.

A princípio, as hipóteses de trabalho propostas nesta pesquisa foram as seguintes:

- O uso de pistas contextuais facilita o reconhecimento de palavras, possibilitando a leitura (em contexto) daquelas palavras que os sujeitos não conseguem ler isoladamente.

- Os "bons" leitores (alunos do grupo 3) demonstram maior aptidão para utilizar pistas do contexto quando comparados com os demais sujeitos da pesquisa: os leitores iniciantes (alunos do grupo 2) e os sujeitos com dificuldades em leitura (alunos do grupo 1).

\section{MÉTODO}

\section{Participantes}

O universo da pesquisa é formado por alunos da $1^{\mathrm{a}}, 3^{\mathrm{a}}$ e $4^{\mathrm{a}}$ séries do Ensino Fundamental de escolas da Rede Municipal de Ensino de Curitiba que possuem salas de recursos. ${ }^{4}$

Do referido universo (que abrange 20 instituições escolares, agrupadas em sete núcleos), foram escolhidas aleatoriamente seis escolas. Após obter o consentimento dos responsáveis pelas instituições para a realização da investigação científica pretendida, a pesquisadora aplicou o Teste de Desempenho Escolar -TDE - (Stein, 1994) aos alunos das salas de recursos indicados pelos professores como de fraco desempenho em leitura. Com base nos resultados do TDE, o presente estudo ficou restrito a três escolas, onde foram identificados 20 alunos com dificuldades em leitura, os quais compuseram o grupo 1. Emparelhados a ele, foram selecionados outros dois grupos. Assim, foram formados três grupos, a saber:

- Grupo 1 - composto por 20 alunos (14 da $4^{\text {a }}$ série e 6 da $3^{\mathrm{a}}$ série) com idades variando de 10 a 13 anos e 6 meses (média 11 anos e 6 meses) que freqüentavam salas de recursos e apresentavam dificuldades em leitura. Esses alunos, selecionados pelo TDE, obtiveram em leitura escores muito inferiores ao esperado para a sua série, embora tivessem obtido em

4 Em relação às salas de recursos, é importante ressaltar que elas "foram implantadas na Rede Municipal de Ensino a partir da necessidade de se oferecer atendimento aos alunos que apresentavam Dificuldades de Aprendizagem (...), cujas características não recomendavam atendimento em Classe Especial." (Curitiba, 1992, p. 50). 
- Grupo 2 - composto por 20 alunos da 1. a série com idades variando de 6 anos e 3 meses a 7 anos e 10 meses (média 7 anos e 1 mês), emparelhados com os sujeitos do Grupo 1 pelo nível de leitura ${ }^{5}$. Também foram selecionados de acordo com os resultados do teste TDE, tendo obtido escores em leitura adequados à sua série. Portanto, eram alunos que não apresentavam dificuldades de leitura e tinham idade cronológica inferior à dos alunos do grupo 1 .

- Grupo 3 - composto por 20 alunos (14 da $4^{\text {a }}$ série e 6 da $3^{\text {a }}$ série) provenientes das mesmas turmas (salas regulares) que os alunos do Grupo 1 e com eles emparelhados de acordo com a idade cronológica, ou seja, com idades variando de 10 anos a 13 anos e 1 mês (média 11 anos e 1 mês). Para a seleção desses sujeitos, além do critério de idade, foi utilizado também o teste TDE, a fim de verificar se obtinham escores em leitura adequados às suas séries. Logo, eram alunos sem dificuldades em leitura e com a mesma idade cronológica dos sujeitos do grupo 1 .

De acordo com os dados fornecidos pelas equipes pedagógico-administrativas das escolas, os alunos são oriundos de famílias com renda familiar de dois a cinco salários mínimos. Além disso, a escolaridade média de seus pais é a de $1^{\circ}$ grau. Com base nesses dados, considerou-se que não havia variação socioeconômica significativa entre os sujeitos pesquisados.

\section{Material e procedimento}

O presente estudo foi baseado em três tipos de provas experimentais: medidas de controle, tarefa de leitura de palavras isoladas e tarefa de facilitação contextual na leitura.

\section{Medidas de controle ${ }^{6}$}

Foram usadas as mesmas medidas de controle utilizadas no estudo de Rego (1995): uma medida de

5 Delineamentos de pesquisa com grupo de controle emparelhado pela idade de leitura têm sido usados por diversos pesquisadores (Bryant \& Bradley, 1985/1987; Bryant, Nunes \& Bindman, 1997; Guthrie, 1973; Tunmer, Nesdale \& Wright, 1987). Eles são apropriados para verificar se existem diferenças entre o padrão de leitura das crianças com dificuldades nesta área e o padrão de leitura dos leitores principiantes.

6 Embora no delineamento do presente estudo não tenha sido previsto o controle da variação lingüística, ou seja, não tenha sido avaliada a distância entre a fala da criança e a norma-padrão utilizada na escola, acentua-se que esta é uma variável que pode estar significativamente relacionada ao desenvolvimento da leitura e da escrita (Barrera, 2000). Registra-se, portanto, a necessidade de incluir esta variável em futuros estudos. inteligência, realizada por meio do teste das Matrizes Progressivas Coloridas de J. C. Raven, e uma tarefa de memória verbal. Entretanto, para os sujeitos com mais de 11 anos e 8 meses, foi utilizado o teste de Matrizes Progressivas - Escala Geral.

O objetivo de efetuar uma medida de controle da inteligência neste estudo deve-se ao fato de que a inteligência é uma variável freqüentemente associada ao sucesso escolar.

Já a tarefa de controle da memória verbal foi considerada em razão de a leitura envolver a retenção de informações verbais na memória a curto prazo. Sua utilização objetivou controlar os eventuais efeitos desse tipo de memória. Para isso, foi solicitado às crianças que repetissem literalmente as 14 sentenças (duas de treinamento e doze de exame) ditas pela pesquisadora. Essas sentenças apresentavam tamanho e nível de complexidade crescentes. A primeira sentença que a criança deveria repetir era "Ontem choveu muito" e a última era "Carlos bebeu o leite porque ele gosta de brincar com Luiz quando está em casa".

Antes de iniciar a tarefa propriamente dita, a pesquisadora praticava com a criança as duas sentenças de treino. $\mathrm{O}$ escore de acerto podia variar de 0 a 12 , pois as crianças recebiam um ponto para cada uma das 12 sentenças que conseguissem repetir corretamente.

\section{Tarefa de leitura de palavras isoladas ${ }^{8}$}

Essa prova consiste na leitura, pelos sujeitos, de 36 palavras apresentadas isoladamente em cartões

\footnotetext{
Como esclarecem Sierra \& Carretero (1993/1996) “a memória a curto prazo tem uma capacidade limitada. Concretamente, de sete elementos (mais ou menos dois, segundo as ocasiões) e uma duração que oscila entre vinte e trinta segundos" (p. 124). Assim, com o objetivo de verificar se havia diferença na capacidade dos sujeitos em reter informações verbais na memória a curto prazo, foram utilizadas, na tarefa de memória verbal, 12 sentenças cujos tamanhos variaram de 3 a 15 palavras, ou seja, sentenças com tamanho maior que a capacidade normal de armazenagem a curto prazo, justamente para investigar o número máximo de elementos que os sujeitos conseguiam temporariamente reter.

8 Conforme Ellis (1993/1995), modelos de reconhecimento de palavras isoladas têm sido propostos na tentativa de caracterizar alguns dos processos mentais que possibilitam ao leitor identificar e pronunciar as palavras escritas. Assim, sugere-se que a leitura da escrita alfabética pode ocorrer pelo menos de duas maneiras: por meio de um processo visual direto ou de um processo envolvendo mediação fonológica. A estrutura desses modelos de leitura baseia-se na distinção entre 0 procedimento lexical e sublexical, ou seja, entre a pronúncia extraída como um todo e a pronúncia obtida por decodificação.
} 
individuais tamanho $7 \times 4,5 \mathrm{~cm}$, tendo sido as letras impressas em fonte Arial (18 pontos e caixa baixa).

As palavras que compõem a prova foram extraídas de Pinheiro (1994), a qual, a partir de uma investigação de freqüência de ocorrência de palavras em livros de leitura da escola primária, dividiu as palavras em duas categorias:alta freqüência e baixa freqüência de ocorrência. Além disso, Pinheiro (1994) dividiu as duas categorias acima em três subcategorias (regular, regra e irregular), de acordo com o relacionamento somletra na ortografia da língua portuguesa. Destacase que essa última classificação considera as irregularidades (relações não-biunívocas) na correspondência letra-som e som-letra que são marcadas na ortografia, muitas das palavras classificadas como irregulares não causam nenhum problema na leitura. ${ }^{9}$ De acordo com Alvarenga (1988), a leitura, diferentemente da escrita, é na sua quase totalidade controlada por regras. Uma das exceções é que não existe regra que possibilite a previsão da leitura correta das palavras nas quais a unidade gráfica $x$ aparece em ambiente intervocálico. Portanto, ora $x$ representa /z/ como em exame, ora representa /š/ como em vexame, ora representa $/ \mathrm{ks} / \mathrm{como}$ em boxe, ora não representa nenhum som específico, como em exceto.

O total de palavras que compõe a tarefa de leitura está dividido em:

- seis palavras regulares de alta freqüência: festa, papai, chuva, café, folhas, palavra;

- seis palavras regulares de baixa freqüência: vila, cabras, batalha, jipe, pesca, moeda;

- seis palavras-regra de alta freqüência: casa, galinha, pás $\underline{s}$ aro disse, também, redação;

- seis palavras-regra de baixa freqüência: nora,

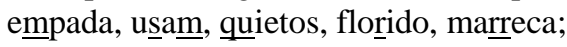

- seis palavras irregulares de alta freqüência: hoje, feliz, amanhã, onça, mamãe, dezena;

- seis palavras irregulares de baixa frequiência: boxe, açude, hino, luzese, xerife, descida.

9 É importante salientar que se poderia ter utilizado palavras classificadas (como regular, irregular e regra) do ponto de vista da leitura. O motivo de se manter a classificação de Pinheiro (1994) foi o de repetir fielmente as palavras que a autora utilizou em seu estudo. Além disso, na presente pesquisa, os dados considerados relevantes estão mais relacionados à variável "freqüência de ocorrência" do que com a variável "regularidade da palavra" (Resultados e Discussão).

\section{Tarefa de facilitação contextual na leitura}

Essa tarefa foi elaborada para verificar se as crianças que não conseguem ler determinadas palavras isoladamente, mas possuem boa sensibilidade para a estrutura sintática das sentenças, usam o contexto de forma eficiente na leitura.

Esse tipo de tarefa foi utilizado por Rego e Bryant (1993) com crianças falantes do inglês e, posteriormente, por Rego (1995) com crianças falantes do português. A utilização de um contexto prévio ativa o léxico mental do leitor, facilitando a identificação das palavras que serão lidas. Desse modo, a combinação da pista contextual com o conhecimento (mesmo que parcial) sobre a grafia da palavra permite ao sujeito uma leitura correta.

A presente tarefa foi elaborada a partir das 12 palavras-regra ( 6 de alta freqüência e 6 de baixa freqüência) e das 6 palavras irregulares de baixa freqüência utilizadas na tarefa de leitura de palavras isoladas. Portanto, foi elaborada a partir das seguintes palavras: casa, galinha, pássaro, nora, empada, usam, disse, também, redação, quietos, florido, marreca, boxe, açude, hino, luzes, xerife e descida.

Para cada uma das 18 palavras foi criado um contexto. As crianças que não conseguiram ler corretamente algumas dessas palavras (quando apresentadas isoladamente - tarefa 2) foram novamente submetidas à leitura das mesmas, com a diferença de que, nesta tarefa, as palavras eram precedidas de um contexto oral.

A criança era introduzida a esta tarefa com a seguinte instrução:

Eu vou te dar uma pista. Escuta bem o que eu vou falar, porque esta pista vai te ajudar a ler a palavra que eu vou te mostrar.

A pesquisadora falava, então, a sentença-estímulo. Em seguida, mostrava a palavra-teste escrita em um cartão para que as crianças a lessem.

O material utilizado foi composto pelos mesmos cartões usados na tarefa de leitura de palavras isoladas (cartões de 7 x 4,5cm com letras impressas em fonte Arial - 18 pontos e caixa baixa).

$\mathrm{O}$ número de itens nessa tarefa pode variar de 0 a 18, correspondendo ao número de palavras apresentadas (entre as 18 desta tarefa que a criança não conseguia ler isoladamente). $\mathrm{O}$ escore obtido pode variar de 0 a $100 \%$ e corresponde à proporção entre as palavras lidas corretamente com o apoio do contexto e o número de palavras apresentadas (ou seja, se forem mostradas à criança apenas duas 
palavras e ela ler corretamente uma delas, terá um escore de $50 \%$ ).

Os contextos criados para cada uma das palavras são mostrados na Tabela 1 .

Tabela 1. Contextos criados para cada uma das palavras da tarefa de Facilitação Contextual na Leitura

\begin{tabular}{|c|c|}
\hline Contexto Oral & Palavra Impressa \\
\hline - Ricardo e Priscila gostaram daquela & - casa \\
\hline - A cozinheira fez uma sopa de & - galinha \\
\hline - Meu tio comprou uma gaiola com um lindo & - pássaro \\
\hline - Minha mãe tem três netos, dois genros e uma & - nora \\
\hline - Na festa tinha muitos tipos de salgadinhos, mas Juliana sócomeu & empada \\
\hline - Elas compraram roupas diferentes daquelas que normalmente & - usam \\
\hline $\begin{array}{l}\text { - "Independência ou morte". Esta é a frase mais importante } \\
\text { que ele___. }\end{array}$ & - disse \\
\hline - Meu irmão foi para a praia e o nosso vizinho foi $\_$. & - também \\
\hline - A professora mandou duas tarefas para casa: a leitura de um texto e uma & - redação \\
\hline - A mãe pediu que os filhos ficassem & - quietos \\
\hline - O jardim da minha avó está ___ & - florido \\
\hline - Na fazenda havia várias aves domésticas: galinhas, patos e uma & - marreca \\
\hline - O namorado da minha irmã é campeão de & - boxe \\
\hline - Há muitos peixes no & - açude \\
\hline - As crianças ouviram o & - hino \\
\hline - Na época de natal a cidade fica cheia de & - luzes \\
\hline - Esta é uma estrela de & - xerife \\
\hline $\begin{array}{l}\text { - O carro estava sem bateria, mas o motorista conseguiu fazer com que } \\
\text { ele pegasse na }\end{array}$ & - descida \\
\hline
\end{tabular}

\section{RESULTADOS}

\section{Medidas de controle}

A Tabela 2 mostra a média com o respectivo desvio-padrão dos escores obtidos na tarefa de memória verbal, bem como a média e o desvio-padrão dos escores Z no teste das Matrizes Progressivas de Raven.
Tabela 2. Média e desvio-padrão dos escores obtidos na tarefa de Memória Verbal e no Teste das Matrizes Progressivas

\begin{tabular}{lcccccc}
\hline & & & \multicolumn{2}{c}{$\begin{array}{c}\text { Memória Verbal } \\
(\mathbf{1 2} \text { sentenças) }\end{array}$} & \multicolumn{2}{c}{$\begin{array}{c}\text { Raven } \\
\text { (escores Z) }\end{array}$} \\
\hline Grupo & $\boldsymbol{n}$ & Idade(média) & $M$ & $D P$ & $M$ & $D P$ \\
1 & 20 & 11 a. $6 \mathrm{~m}$. & 9,00 & 1,12 & 0,52 & 0,40 \\
2 & 20 & 7 a. $1 \mathrm{~m}$. & 8,10 & 1,17 & 0,63 & 0,52 \\
3 & 20 & 11 a. $5 \mathrm{~m}$. & 9,00 & 1,34 & 0,54 & 0,40 \\
\hline Total & $\mathbf{6 0}$ & $\mathbf{1 0 a}$. & $\mathbf{8 , 7 0}$ & $\mathbf{1 , 2 7}$ & $\mathbf{0 , 5 6}$ & $\mathbf{0 , 4 4}$ \\
\hline
\end{tabular}

Como se pode observar na Tabela 2, os escores em memória verbal estão mais relacionados à idade do que ao nível de leitura.

A comparação das médias utilizando a ANOVA (one-way) mostrou que a diferença entre os grupos é significativa $[F(2,57)=3,67 ; p<0,03]$. Entretanto, a comparação dos grupos em pares, usando o teste post hoc de Scheffé, mostrou que não existe nenhum par em que os grupos sejam significativamente diferentes. Ou seja, a comparação entre os grupos 1 e 2 apresentou: diferença média $=0,90 ; p=0,072$. Já a comparação entre os grupos 1 e 3 mostrou: diferença média $=0,00 ; p=1,00$. Por último, a comparação entre os grupos 2 e 3 apresentou: diferença média = 0,$90 ; p=0,072$. Assim, infere-se que qualquer diferença de desempenho entre os grupos nas outras tarefas não pode ser atribuída à memória verbal.

Em relação ao teste das Matrizes Progressivas, os resultados demonstram que o grupo 2 tem uma média ligeiramente superior aos outros dois grupos. No entanto, a comparação das médias utilizando-se a ANOVA (oneway) mostrou que essa diferença não é significativa [ $F$ $(2,57)=0,36 ; p>0,70]$. Portanto, os resultados indicam que quaisquer diferenças que venham a ser encontradas nas outras tarefas não poderão ser atribuídas às habilidades medidas pelo teste do Raven.

\section{Tarefa de leitura de palavras isoladas}

Na Tabela 3 são apresentados os escores obtidos pelos sujeitos de cada um dos três grupos, na tarefa de leitura de palavras isoladas.

Tabela 3. Média e desvio-padrão dos escores de Leitura de Palavras Isoladas (por grupo)

\begin{tabular}{|c|c|c|c|c|c|c|c|c|c|c|c|c|c|c|c|c|c|}
\hline \multirow{4}{*}{ Grupo } & \multirow{4}{*}{$n$} & \multicolumn{16}{|c|}{ Leitura de Palavras Isoladas } \\
\hline & & \multicolumn{8}{|c|}{ Alta Freqüência } & \multicolumn{8}{|c|}{ Baixa Freqüîncia } \\
\hline & & \multicolumn{2}{|c|}{$\begin{array}{c}\text { Regular } \\
\text { (6 palavras) }\end{array}$} & \multicolumn{2}{|c|}{$\begin{array}{c}\text { Regra } \\
\text { (6 palavras) }\end{array}$} & \multicolumn{2}{|c|}{$\begin{array}{c}\text { Irregular } \\
\text { (6 palavras) }\end{array}$} & \multicolumn{2}{|c|}{$\begin{array}{c}\text { Total } \\
\text { (18 palavras) }\end{array}$} & \multicolumn{2}{|c|}{$\begin{array}{c}\text { Regular } \\
\text { (6 palavras) }\end{array}$} & \multicolumn{2}{|c|}{$\begin{array}{c}\text { Regra } \\
\text { (6 palavras) }\end{array}$} & \multicolumn{2}{|c|}{$\begin{array}{c}\text { Irregular } \\
\text { (6 palavras) }\end{array}$} & \multicolumn{2}{|c|}{$\begin{array}{c}\text { Total } \\
\text { (18 palavras) }\end{array}$} \\
\hline & & $M$ & $D P$ & $M$ & $D P$ & $M$ & $D P$ & $M$ & $D P$ & $M$ & $D P$ & $M$ & $D P$ & $M$ & $D P$ & $M$ & $D P$ \\
\hline 1 & 20 & 5,60 & 0,75 & 4,90 & 1,17 & 5,05 & 1,28 & 15,55 & 2,80 & 5,00 & 1,08 & 4,10 & 1,45 & 3,95 & 0,94 & 13,05 & 2,37 \\
\hline 2 & 20 & 5,25 & 1,12 & 5,25 & 1,02 & 4,75 & 1,29 & 15,25 & 2,81 & 5,20 & 0,77 & 3,70 & 1,59 & 4,45 & 0,89 & 13,35 & 2,78 \\
\hline 3 & 20 & 6,00 & - & 6,00 & - & 6,00 & - & 18,00 & - & 6,00 & - & 5,70 & 4,47 & 5,45 & 0,51 & 17,15 & 0,81 \\
\hline Total & 60 & 5,62 & $\mathbf{0 , 8 3}$ & 5,38 & 0,99 & 5,27 & 1,16 & 16,27 & 2,57 & 5,40 & $\mathbf{0 , 8 7}$ & 4,50 & 1,52 & 4,62 & 1,01 & 14,52 & 2,84 \\
\hline
\end{tabular}


A Tabela 3 mostra que, como se esperava, os sujeitos do grupo 3 apresentaram melhor desempenho que os dos outros grupos em todas as condições. Além disso, como pode ser observado, independentemente do grupo, os sujeitos tiveram melhor desempenho na leitura de palavras de alta frequiência. ${ }^{10}$ Para confirmar estes resultados, foi efetuada uma análise de variância para medidas repetidas, que teve como fator intra-sujeitos o efeito freqüência (alta e baixa) e como fator intersujeitos os grupos (cf. Tabela 4).

Tabela 4. Resultado da análise de variância para medidas repetidas utilizada para verificar a diferença de desempenho na leitura em função do fator "freqüência de ocorrência"

\begin{tabular}{lccccc}
\hline Fonte & $\begin{array}{c}\text { Soma dos } \\
\text { Quadrados }\end{array}$ & $g l$ & $\begin{array}{c}\text { Média dos } \\
\text { quadrados }\end{array}$ & $F$ & Sig \\
\hline Freqüência & 91,88 & 1 & 91,88 & 59,73 & 0,000 \\
Freqüência x & 13,95 & 2 & 6,98 & 4,54 & 0,015 \\
Grupo & & & & & \\
Erro & 87,68 & 57 & 1,54 & & \\
Constante & 28428,41 & 1 & 28428,41 & 3396,57 & 0,000 \\
Grupo & 286,02 & 2 & 143,01 & 17,09 & 0,000 \\
Erro & 477,08 & 57 & 8,37 & & \\
\hline
\end{tabular}

A análise de variância mostrou um efeito significativo de freqüência $[F(1,57)=59,73 ; p<0,001]$, bem como uma diferença significativa no desempenho dos três grupos $[F(2,57)=17,09 ; p<0,001]$. Com a utilização do teste post hoc de Scheffé, confirma-se que as diferenças entre os grupos se devem ao desempenho significativamente melhor do grupo $3 \mathrm{em}$ relação aos outros dois grupos; não existe diferença significativa entre os grupos 1 e 2 (o que era de esperar, uma vez que eles foram emparelhados pelo nível de leitura). A seguir serão mostrados os resultados da comparação efetuada entre os grupos por meio do teste post hoc de Scheffé. A comparação entre os grupos 1 e 2 mostrou: diferença média $=0,00$; $p=1,00$. Por sua vez, a comparação entre os grupos 1

10 Entre os fatores psicolingüísticos que afetam o reconhecimento de palavras, destaca-se o fator freqüência, que se refere ao grau de ocorrência de certa palavra na língua. Como algumas palavras ocorrem com alta freqüência, enquanto outras ocorrem com baixa freqüência, as primeiras são mais familiares do que as segundas. Assim, quanto maior a frequiência de ocorrência das palavras, tanto maior a probabilidade de que elas sejam lidas utilizando-se um procedimento visual (lexical). Por outro lado, as palavras de baixa freqüência tendem a ser lidas utilizandose a mediação fonológica (procedimento sublexical), na medida em que os sujeitos não possuem representações ortográficas destas palavras estocadas na memória, pois estas representações são formadas a partir de exposições repetidas às palavras escritas. e 3 apontou: diferença média $=3,28 ; p<0,001$. Por último, a comparação entre os grupos 2 e 3 apresentou: diferença média $==3,28 ; p<0,001$.

Foi observado também um efeito significativo de interação Grupo X Freqüência $[F(2,57)=4,54 ; p<$ $0,05]$. Esse efeito se deve ao fato de o grupo 1, quando comparado ao grupo 2, demonstrar melhor desempenho na leitura de palavras de alta freqüência e pior desempenho na leitura de palavras de baixa freqüência. Isso pode ser confirmado na tabela 3 .

\section{Tarefa de facilitação contextual na leitura}

Para verificar em que medida os três grupos de sujeitos utilizam o contexto de forma a lhes facilitar a leitura, foi empregada a tarefa de facilitação contextual, em que era solicitado que os sujeitos lessem, no contexto de uma frase, as mesmas palavras que não tinham conseguido ler isoladamente.

$\mathrm{O}$ número de palavras que cada um dos sujeitos leu variou de acordo com o número de palavras isoladas que não conseguiu ler isoladamente (tarefa 2). Os que não conseguiram ler isoladamente apenas uma das palavras que seriam apresentadas no contexto não realizaram esta tarefa.

$\mathrm{Na}$ análise dos resultados, foi considerado o escore das crianças em porcentagens, o qual corresponde à proporção entre as palavras lidas corretamente com o apoio do contexto e o número de palavras apresentadas.

Na Tabela 5 são mostrados o número máximo, o mínimo e a média de palavras apresentadas em contexto, bem como as porcentagens de acertos efetuados pelos sujeitos dos três grupos nessa tarefa.

Tabela 5 - Número máximo, mínimo, média e desviopadrão das palavras apresentadas e das porcentagens de acertos na tarefa de Facilitação Contextual na Leitura (por grupo)

\begin{tabular}{cccccccccc}
\hline & \multicolumn{4}{c}{$\begin{array}{c}\text { Número de Palavras } \\
\text { Apresentadas }\end{array}$} & \multicolumn{5}{c}{ Porcentagens de Acertos } \\
\hline $\begin{array}{c}\text { Grup } \\
\text { o }\end{array}$ & $\boldsymbol{n}$ & E.Min. & E.Max. & $M$ & DP & E.Min. & E.Max. & $M$ & $D P$ \\
\hline 1 & 20 & 2 & 12 & 5,05 & 2,65 & 25,00 & 100,00 & 75,18 & 23,60 \\
2 & 17 & 2 & 9 & 5,06 & 1,98 & 28,57 & 100,00 & 70,97 & 24,40 \\
3 & 5 & 2 & 2 & 2,00 & - & 50,00 & 100,00 & 90,00 & 22,36 \\
\hline Total & $\mathbf{4 2}$ & $\mathbf{2}$ & $\mathbf{1 2}$ & $\mathbf{4 , 6 9}$ & $\mathbf{2 , 4 0}$ & $\mathbf{2 5 , 0 0}$ & $\mathbf{1 0 0 , 0 0}$ & $\mathbf{7 5 , 2 4}$ & $\mathbf{2 3 , 9 4}$ \\
\hline
\end{tabular}

Como pode ser observado, apenas um quarto dos sujeitos do grupo 3 realizou essa tarefa, porque a maioria não tinha cometido erros na leitura de palavras isoladas. No grupo 2, a tarefa não foi realizada por três sujeitos. Já no grupo 1, todos precisaram de apoio contextual para ler algumas palavras, o que facilitou a leitura de $75,18 \%$ das palavras (em média). 
A Tabela 5 mostra ainda que os grupos 1 e 2 apresentaram resultados bastante semelhantes, quer em relação à média de palavras que não haviam conseguido ler isoladamente, quer em relação à porcentagem média de acertos na leitura facilitada pelo contexto. Como as distribuições não eram normais, foi utilizado o teste de Mann-Whitney para comparar o desempenho dos dois grupos. Os resultados dessa análise confirmam que não existe uma diferença significativa entre os grupos 1 e 2 ( $p$ > $0,10)$.

\section{DISCUSSÃO}

Sintetizando vários elementos apresentados na introdução, pode-se dizer que, de acordo com os modelos da leitura de orientação ascendente (bottom$u p$ ), as diferenças de desempenho na leitura estão na decodificação. Para os modelos de orientação descendente (top-down), o desempenho do leitor está relacionado à sua capacidade de identificar as palavras dedutivamente, utilizando pistas semânticas, sintáticas e visuais do texto.

Assim, considerando-se que a leitura não depende unicamente do processo de decodificação, mas também de pistas grafofônicas, semânticas e sintáticas, formulou-se a hipótese de que o uso de pistas contextuais facilita o reconhecimento de palavras, possibilitando a leitura (em contexto) daquelas palavras que os sujeitos não conseguem ler isoladamente. Além disso, esperava-se que os "bons" leitores (alunos do grupo 3) apresentassem maior aptidão para utilizar pistas do contexto, quando comparados com os demais sujeitos da pesquisa.

Desse modo, para avaliar o desempenho em leitura dos sujeitos pesquisados e verificar como a utilização de pistas do contexto verbal pode aumentar esse desempenho, foram utilizadas, além das medidas de controle, dois tipos de provas: leitura de palavras isoladas e em contexto verbal.

Ao focalizar os resultados relativos à tarefa de leitura de palavras isoladas, verificou-se, em todos os grupos, maior eficiência em relação às palavras de alta freqüência. Portanto, não se verifica uma diferença entre os procedimentos utilizados pelas crianças com e sem dificuldades, mesmo quando considerado o grupo 3 , que apresentou um nível de leitura mais avançado que o dos outros grupos. Na verdade, os dados coletados na tarefa de leitura de palavras isoladas evidenciam que todos os grupos apresentaram melhor desempenho no reconhecimento de palavras em que era possível a utilização do procedimento visual (nãoanalítico).
Além disso, é importante ressaltar que os alunos do grupo 1 - embora selecionados segundo o critério de dificuldade em leitura - apresentam uma média de acertos na tarefa de leitura de palavras isoladas que ultrapassa $75 \%$ do total de palavras (cf. Tabela 3). Logo, com base em seu desempenho, pode-se dizer que os sujeitos do grupo 1 já compreenderam o princípio alfabético, embora não possuam um domínio pleno da leitura.

Enfim, verificou-se que, ao ler, as crianças dos grupos investigados não se apóiam apenas no processo de decodificação, mas utilizam outras fontes de informações. Ou seja, mesmo no nível da palavra, o leitor não depende apenas de estratégias ascendentes. Como explica Kato (1985), com o crescimento do léxico visual do aprendiz e sua familiaridade com os segmentos mais freqüentes da língua, o reconhecimento da palavra passa a se dar de forma instantânea.

No que se refere à tarefa de leitura de palavras em contexto, os resultados obtidos mostram que os sujeitos dos grupos 1 e 2 apresentam uma média de acertos praticamente igual e, de acordo com o teste de Mann-Whitney, não existe uma diferença significativa entre esses dois grupos. Portanto, apenas o grupo 3 apresentou um desempenho melhor que os outros.

Considerando-se apenas os alunos da mesma idade cronológica (grupos 1 e 3 ), verifica-se que todos os sujeitos do grupo 1 realizaram essa tarefa (observa-se que não tinham conseguido ler isoladamente uma média de 5,05 palavras). No grupo 3 apenas um quarto dos sujeitos realizou a tarefa; todos deixaram de ler isoladamente duas palavras. Além disso, dos cinco sujeitos do grupo 3 que realizaram essa tarefa, apenas um deixou de ler corretamente uma das duas palavras apresentadas no contexto.

Destarte, os resultados relativos aos grupos 1 e 3 , aqui apresentados, estão de acordo com aqueles do estudo de Perfetti, Goldman e Hogaboam (1979), os quais verificaram que os "bons" leitores eram menos dependentes das pistas contextuais para reconhecer palavras na leitura. Esses autores também concluíram que os "bons" leitores exibiam uma aptidão significativamente superior à dos "maus" leitores para fazer uso de pistas contextuais em tarefas que mediam essa habilidade. Esta afirmação não pôde ser verificada neste estudo, devido ao pequeno número de palavras apresentadas aos poucos sujeitos do grupo 3 que realizaram a tarefa.

É interessante observar ainda que os alunos do grupo 1 apresentaram $75,18 \%$ de acertos na leitura contextualizada. Logo, esses sujeitos efetivamente procuraram apoio no contexto verbal para compensar 
as suas dificuldades de decodificação. Portanto, suas dificuldades de leitura em atividades diárias não parecem estar na falta de habilidade para usar o contexto na leitura das palavras menos familiares, mas na sua pouca capacidade de construir um contexto facilitador para a leitura. Ou seja, eles não conseguem ler com presteza um número de palavras suficiente para formar um texto significativo, que sirva de apoio à leitura de outras palavras.

Analisando os resultados desta pesquisa, pode-se perceber a ineficácia de tentar explicar o processo de leitura adotando um dos dois modelos extremos (ascendente ou descendente). Na realidade, este estudo aponta para a complementaridade desses dois modelos. Em outras palavras, acredita-se que as estratégias ascendentes e descendentes coexistem na leitura, como sugerem os autores que propõem os modelos interativos (Perfetti, 1992; Stanovich, 1980).

Estes dados têm interessantes implicações educacionais, pois sugerem que, para propiciar aos alunos um domínio pleno da leitura, devem-se equilibrar atividades que estimulem diretamente a decodificação (instruções fônicas e ensino sistemático do reconhecimento e discriminação dos padrões de correspondência entre ortografia e fonologia) e atividades voltadas para a análise sintático-semântica do texto.

É importante ressaltar que professor e alunos deverão utilizar o texto como objeto de estudo, pois ele é que fornecerá elementos para a reflexão sobre a língua. Enfim, ao sistematizar seu trabalho com texto, o professor deve enfocar tanto a análise das palavras (relações letra/som, padrões silábicos e morfemas) quanto a análise da própria organização do texto (relação entre palavras, frases, orações, períodos e parágrafos).

\section{REFERÊNCIAS}

Alvarenga, D. (1988). Leitura e escrita : dois processos distintos. Educação em Revista, 7, 27-31.

Barrera, S.D. (2000). Linguagem oral e alfabetização: um estudo sobre variação lingüística e consciência metalingüística em crianças da $1^{a}$ série do ensino fundamental. Tese de Doutorado, Não-Publicada, Progrma de Pós-graduação em Psicologia Escolar e do Desenvolvimento Humano, Universidade de São Paulo.

Bryant, P.E., \& Bradley, L. (1987). Problemas de aprendizagem de leitura. (I.C.S. Ortiz, Trad.) Porto Alegre: Artes Médicas. (Trabalho original publicado em 1985).

Bryant, P.; Nunes, T. \& Binddman, M. (1997). Backward readers' awareness of language: Strengths and weaknesses. European Journal of Psychology of Education, 12(4), 357-372.

Byrne, B. (1996). Treinamento da consciência fonêmica em crianças pré-escolares : por que fazê-lo e qual o seu efeito? Em C. Cardoso-Martins (Org.), Consciência fonológica \& alfabetização (pp. 37-67). Petrópolis: Vozes.
Byrne, B. \& Fielding-Barnsley, R. (1993). Evaluation of a program to teach phonemic awareness to young children: A 1-year followup. Journal of Educational Psychology, 85(1), 104-111.

Cunningham, J. W. \& Fitzgerald, J. (1996). Epistemology and reading. Reading Research Quarterly, 31(1), 36-60.

Curitiba. (1992). Prefeitura Municipal de Curitiba. Secretaria Municipal de Educação. Proposta de Educação Especial na Secretaria Municipal de Educação. Curitiba.

Ellis, A. W. (1995). Leitura, escrita e dislexia: uma abordagem cognitiva. (D. Batista, Trad.) Porto Alegre: Artes Médicas. (Trabalho original publicado em 1993).

Goodman, K. S. (1987). O processo de leitura: considerações a respeito das línguas e do desenvolvimento. Em E. Ferreiro \& M. Gomez Palácio (Orgs.), Os processos de leitura e escrita: novas perspectivas (pp.11-22). Porto Alegre: Artes Médicas.

Gottardo, A., Stanovich, K.E. \& Siegel, L.S. (1996). The relationships between phonological sensitivity, syntactic processing, and verbal working memory in the reading performance of thirdgrade children. Journal of Experimental Child Psychology, 63, 563582.

Guthrie, J.T. (1973). Reading comprehension and syntactic responses in good and poor readers. Journal of Educational Psychology, 65(3), 294-299.

Kato, M. A. (1985). O aprendizado da leitura. São Paulo: Martins Fontes.

Perfetti, C. A. (1992). A capacidade para a leitura. Em R. Sternberg, As capacidades intelectuais humanas: uma abordagem em processamento de informações (pp.72-96). Porto Alegre: Artes Médicas.

Perfetti, C. A., Golldman, S. R. \& Hogaboam, T. W. (1979). Reading skill and the identification of words in discourse context. Memory \& Cognition, 7(4), 273-282.

Pinheiro, A. M. V. (1994). Leitura e escrita: uma abordagem cognitiva. Campinas: Editorial Psy II.

Rego, L. L B. (1993). O papel da consciência sintática na aquisição da língua escrita. Temas em Psicologia, 1, 79-87.

Rego, L. L .B. (1995). Diferenças individuais na aprendizagem inicial da leitura: Papel desempenhado por fatores metalinguísticos. Psicologia: Teoria e Pesquisa, 11(1), 51-60.

Rego, L. L. B., \& Bryant, P. E. (1993). The connection between phonological syntactic and semantic skills and children's reading and spelling. European Journal of Psychology of Education, 8(3), 235-246.

Shankweiler, D., Crain, S., Brady, S. \& Macaruso, P. (1992). Identifying the causes of reading disability. Em P. B. Gough, L. C. Ehri \& R. Treiman (Eds.), Reading acquisition (pp. 275-305). Hillsdale: Erlbaum.

Sierra, B., \& Carretero, M. (1996). Aprendizagem, Memória e Processamento da Informação: A Psicologia Cognitiva da Instrução. Em C. Coll, J. Palacios \& A. Marchesi (Orgs.), (A. M. Alves, trad.) Desenvolvimento psicológico e educação: Psicologia da Educação (pp.122-137). Porto Alegre: Artes Médicas. (Trabalho Originalmente publicado em 1993)

Smith, F. (1999). Leitura significativa. (B. A. Neves, Trad.) Porto Alegre: Artes Médicas. (Trabalho original publicado em 1997).

Smith, F. (1984). The creative achievement of literacy. Em H. Goelman, A. Oberg \& F. Smith (Eds.), Awakening to literacy (pp.143-153). Portsmouth, NH: Heinemann. 
Stanovich, K. E. (1980). Toward an interactive-compensatory model of individual differences in the development of reading fluency. Reading Research Quarterly, 16(1), 32-71.

Stanovich, K.E., Cunningham, A.E. \& Cramer, B.B. (1984). Assessing phonological awareness in kindergarten children: issues of task comparability. Journal of Experimental Child Psychology, $38,175-190$

Stein, L.M. (1994). TDE: teste de desempenho escolar: manual para aplicação e interpretação. São Paulo: Casa do Psicólogo.

Tunmer, W.E. (1990). The role of language prediction skills in beginning reading. New Zealand Journal of Educational Studies, 25(2), 95-114.

Tunmer, W. E., Herriman, M. L. \& Nesdale, A. R. (1988). Metalinguistic abilities and beginning reading. Reading Research Quarterly, 23, 134-158.

Tunmer, W. E., \& Hoover, W. A. (1992). Cognitive and linguistic factors in learning to read. Em P. B. Gough, L. C. Ehri \& R.
Treiman (Eds.), Reading acquisition (pp. 175-214). Hillsdale: Erlbaum.

Tunmer, W.E., Nesdale, A.R. \& Wright, A.D. (1987). Syntactic awareness and reading acquisition. British Journal of Developmental Psychology, 5, 25-34.

Van Order, G. C. (1987). A rows is a rose: spelling, sound, and reading. Memory \& Cognition, 15(3), 181-198.

Williams, J. (1980). Teaching decoding with an emphasis on phoneme analysis and phoneme blending. Journal of Educational Psychology, 72(1), 1-15.

Yopp, H.K. (1988). The validity and reliability of phonemic awareness tests. Reading Research Quarterly, 23(2), 159-177.

Recebido em 07/10/2003

Aceito em 15/04/2004

Endereço para correspondência: Sandra Regina Kirchner Guimarães. Departamento de Teoria e Fundamentos da Educação, Setor de Educação, Universidade Federal do Paraná, Rua General Carneiro, 460, $4^{\circ}$ andar, CEP 80060-100, Curitiba PR. E-mail: sonnyg@uol.com.br 